\title{
The influence of mechanical gear on the efficiency of small hydropower
}

\author{
Zbigniew Ferenc ${ }^{1, *}$, and Aleksandra Sambor ${ }^{1}$ \\ ${ }^{1}$ Wroclaw University of Science and Technology, Faculty of Environmental Engineering, Wybrzeze \\ Wyspianskiego 27, 50-370 Wroclaw, Poland
}

\begin{abstract}
Pursuant to the "Strategy of development of renewable energy", an increase in the share of renewable energy sources in the national fuel-energy balance up to $14 \%$ by 2020 is planned in the structure of usage of primary energy carriers. The change in the participation of the clean energy in the energy balance may be done not only by the erection of new and renovation of the already existing plants, but also through an improvement of their energetic efficiency. The study presents the influence of the mechanical gear used on the quantity of energy produced by a small hydropower on the basis of SHP Rzepcze in Opole province in 2005-2010. The primary kinematic system was composed of a Francis turbine of a vertical axis, a toothed intersecting axis gear of 1:1 ratio, a belt gear of a double ratio. After a modernization the system was simplified by means of reducing the intersecting axis gear and the double ratio of the belt gear. The new kinematic system utilized a single-ratio belt gear of a vertical axis. After the kinematic system was rearranged, a significant improvement of efficiency of the small hydropower was concluded, which translates into an increase of the amount of energy produced.
\end{abstract}

\section{Introduction}

Pursuant to the "Strategy of development of renewable energy" [1], approved by the Council of Ministers of 5 September 2000, an increase in the share of renewable energy sources in the national fuel-energy balance up to $14 \%$ by 2020 is planned in the structure of usage of primary energy carriers. Currently the usage of renewable energy in Poland is estimated to be $11.4 \%[2,3]$. Renewable energy sources can have a significant contribution in the energy balance of individual municipalities, guaranteeing regional independence and energy security, as well as adding to an increase of the supply of energy in underdeveloped powertransmission areas.

The following shall be included in renewable energy: hydro-power, wind power, solar power, geothermal power and biomass power. In Poland the share of water energy in total electric energy production is currently on the level of $2.3 \%$ [2]. Small hydropower including the objects of installed capacity up to $5 \mathrm{MW}$ play a major role. Currently in Poland there are approximately 700 small hydropower. These objects are environmentally-friendly (do not cause fundamental changes in landscapes and natural habitats, as compared with big

* Corresponding author: zbigniew.ferenc@pwr.edu.pl 
hydroelectric plants) and positively influence the hydrological balance of adjoining areas, increasing the surface-based and underground retention of water, which influences the levels of groundwater and its melioration. Small hydropower allow to monitor the quality and level of water on a regular basis. Not only do they impose a need to maintain constant technical and operational efficiency of hydrotechnical facilities (stages of fall, weirs, canals, etc.), but also the maintenance and current usage of flumes [5]. Moreover, small hydropower improve the parameters of power grids in the so-called power output terminals, as well as reduce the costs of their modernization. What is more, they affect the reduction of loss related to power transmission.

The change in the participation of the clean energy in the energy balance may be done not only by the erection of new and renovation of the already existing plants, but also through an improvement of their energetic efficiency. The study presents the influence of the mechanical gear used on the quantity of energy produced by a small hydropower on the basis of SHP (SHP: Small HydroPower) Rzepcze in Opole province in 2005-2010.

\section{Original power transmission system}

Originally, the kinematic system was composed of the 110/170 cm Francis turbine of a vertical axis, manufactured by J.M. Voith in 1936, of the following rated capacity: $\mathrm{Q}=1.6 \mathrm{~m}^{3} / \mathrm{s}, \mathrm{N}=72 \mathrm{kM}, \mathrm{n}=120 \mathrm{RPM}, \mathrm{H}=4.1 \mathrm{~m}$ (fig. 1 ), the toothed intersecting axis gear of a 1:1 ratio, as well as the belt gear of a double ratio.

The technical condition of the turbine was assessed sufficient. Numerous corrosion pits were spotted on the surface of rotor blades. Damaged pins and liners were found in the guide apparatus of the turbine [6].

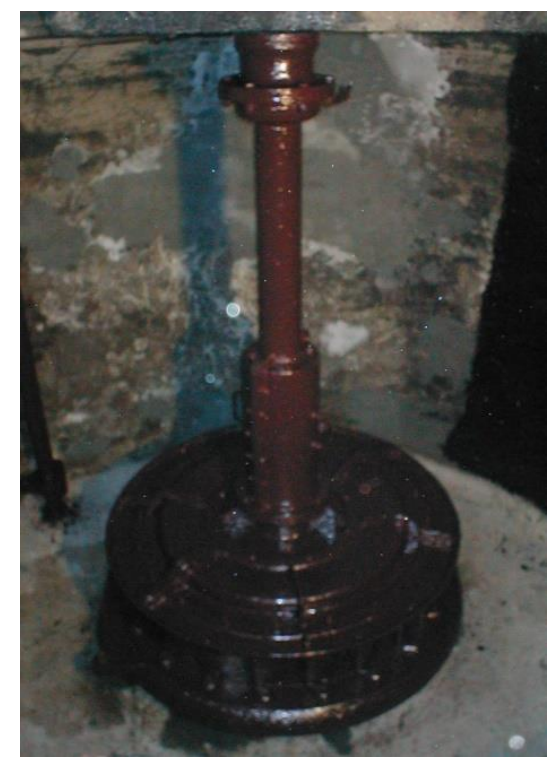

Fig. 1. The 110/170 cm Francis turbine from 1936.

Power take-off from the shaft to the drive shaft was done by means of the intersecting axis toothed gear. Its technical state was unsatisfactory. Its teeth were broken off and the inter-tooth clearances were too big, giving evidence of too big a backlash in the bearing of the turbine shaft. The intersecting axis gear transmitted power to the belt gear of a horizontal axis (fig. 2) my means of a disengaging jaw coupling. The diameter of the pulley was 
$1200 / 800 \mathrm{~mm}$. This pulley was primarily used to drive a bucket elevator of a corn elevator. The same overhead shafting was equipped with a $1700 \mathrm{~mm}$-diameter pulley to power a generator [6].

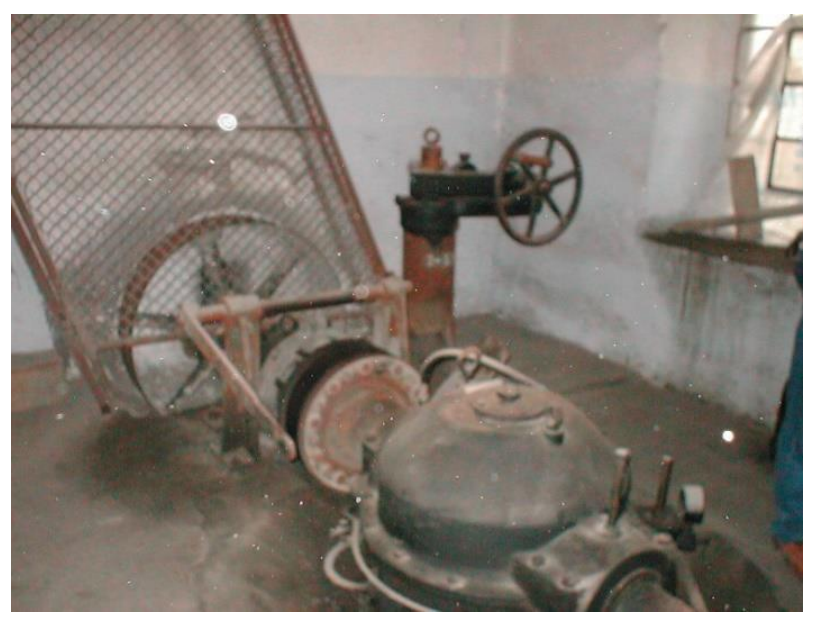

Fig. 2. The belt gear.

\section{Potential spots of reducing power loss in the power transmission system}

The possible spots where power loss in the power transmission system can be achieved:

- inlet channel,

- turbine bearing,

- intersecting axis gear,

- belt gear,

- connection with power generator (coupling),

- properly selected power generator.

The study concerns the problem of energy loss solved my means of modernizing the gear in the power transmission system.

In the first run, the current power transmission system, i.e., the turbine, the toothed intersecting axis gear (fig. 3) and the belt gear underwent a renovation. These works were finished in the second half of 2004. Commissioning was done on 4 December 2004, whereas a 72-hour test run commenced on 8 January 2005. Successively, the plant was connected to the power grid permanently. 


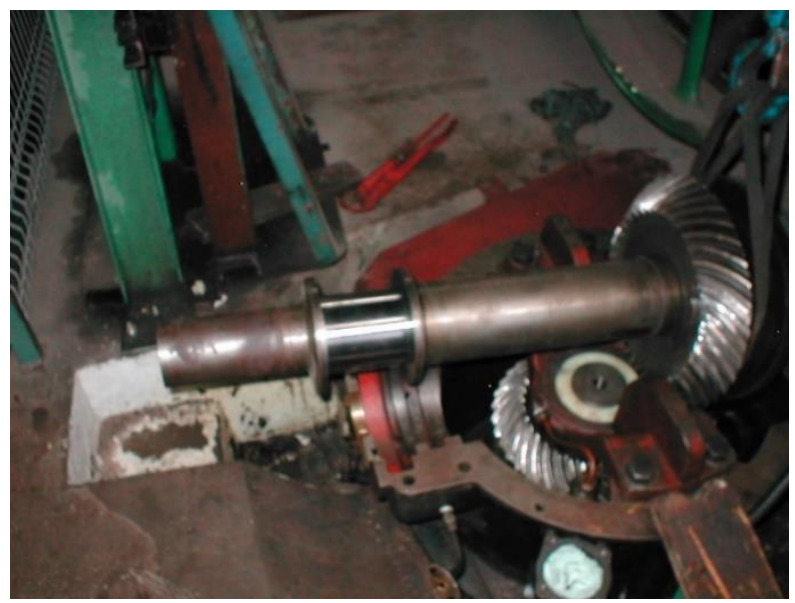

Fig. 3. The toothed intersecting axis gear after the renovation.

Figure 4 presents the factual energy production in SHP Rzepcze in 2005 as dependent on the amount of water flowing through the turbine pit.

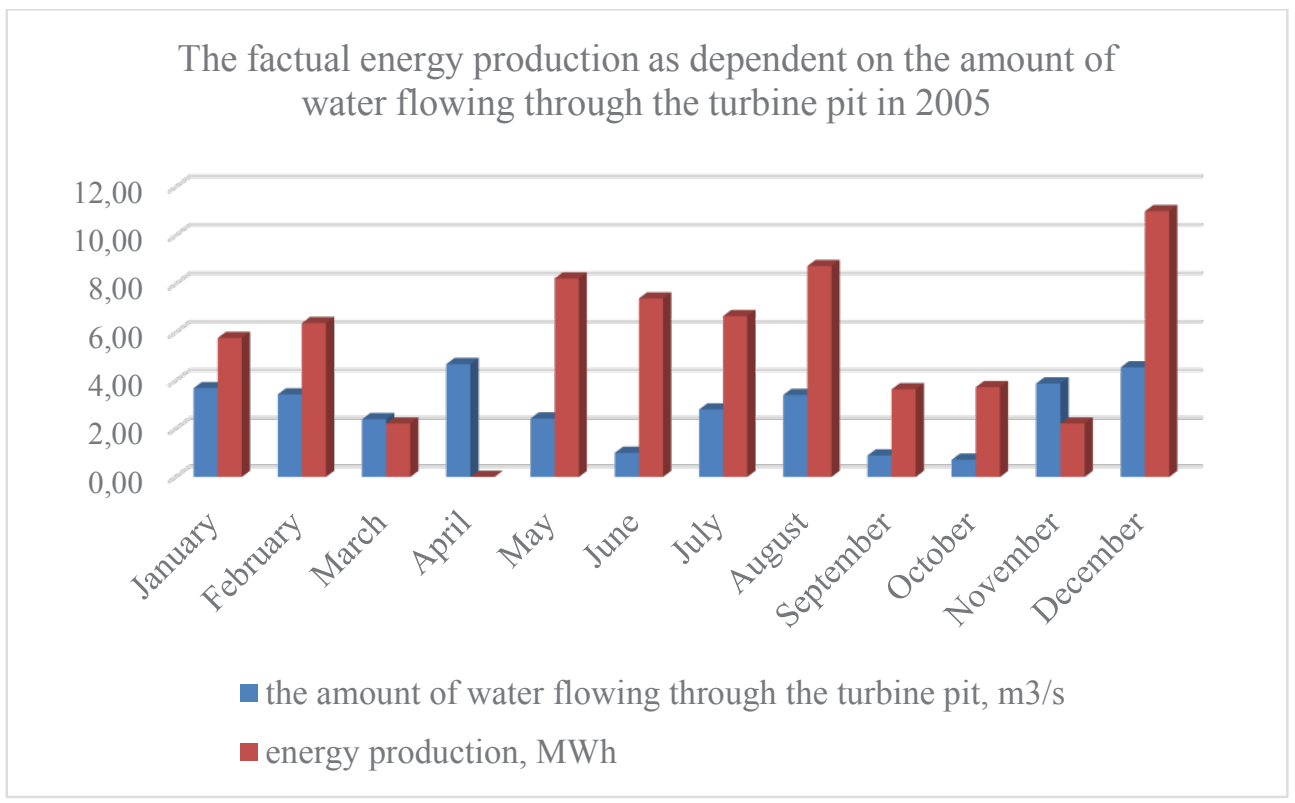

Fig. 4. The factual energy production as dependent on the amount of water flowing through the turbine pit in 2005 .

On the basis of figure 4, it may be concluded that since April 2005 the amount of power generated was on the average level of $4.8 \mathrm{MWh}$ with the rate of turbine pit water flow of $3.2 \mathrm{~m}^{3} / \mathrm{s}$. The degree of energy output as the quotient of energy production to turbine flow rate was only 1.5 . Therefore, it was decided that a modernization of the existing power transmission system should be done in order to achieve the maximum efficiency of energy production and, as a consequence, optimal utilization of all elements of the power transmission system. The works commenced in April 2005. Figure 4 clearly exhibits that 
after the modernization had been done, the degree of power output from the turbine pit water flow increased to 2.6 on average.

\section{Modernized power transmission system}

The modernization of the power transmission gear was done in phases, with gradual elimination of power loss points. In the new kinematic system a single-stage belt gear of a horizontal axis was used, the task of which was to adjust the rotation of the asynchronous generator to the power grid. The gear was composed of a $1840 \mathrm{~mm}$ pulley made of iron cast, a $105 \mathrm{~mm}$ intermediate shaft supported with three bearings, as well as a small $880 \mathrm{~mm}$ pulley (fig. 5). The ratio was 8.41 .

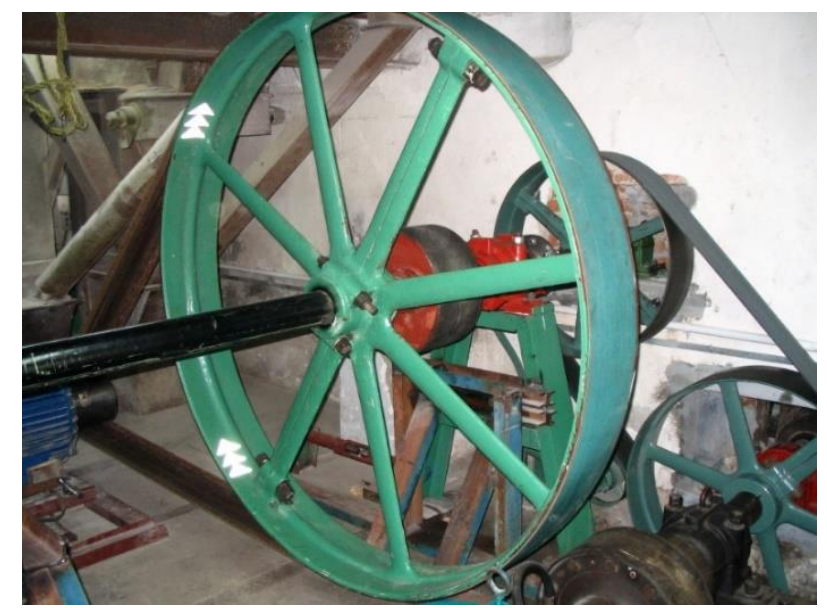

Fig. 5. The modernized belt gear.

After the kinematic system was rearranged, a significant improvement of efficiency of the small hydropower was concluded, which translates into an increase of the amount of energy produced (fig. 6).

Figure 6 clearly exhibits that the energy production increased nearly three times, from approx. $66 \mathrm{MWh} /$ year to $180 \mathrm{MWh} /$ year. The rate of energy output for first quarter in 2005-2008 increased by 6.5 on average, within 6.2 to 6.7. Figure 6 presents distinguished changes in the amount of energy produced depending on season, which directly translates in the state of water level in the river and the water flow. The best period in relation to energy production was Autumn to Spring. The months of outages the reason of which was too small water flow were months of minor energy production. 


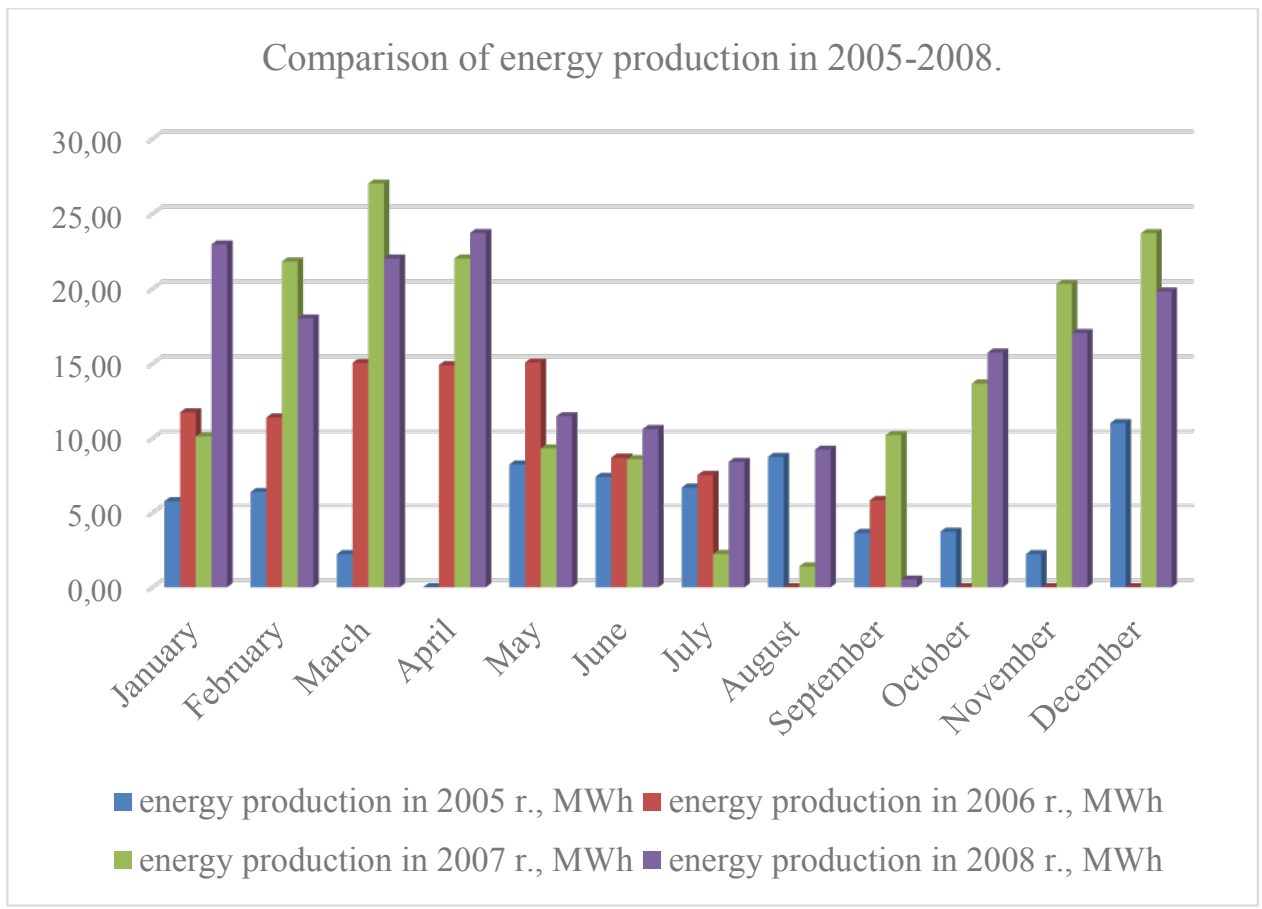

Fig. 6. Comparison of energy production in 2005-2008.

In order to eliminate the two-stage ratio of the gear and to increase the efficiency and reliability of the plant the belt gear was reconstructed to a single-stage belt gear of a vertical axis (fig. 7), which allowed to eliminate the toothed gear from the power transmission system. This was done in October 2008. During the reconstruction the turbine shaft was extended, bearings, including the main axial bearing (slide to rolling bearing) were replaced. The reconstruction allowed to increase the distance between the turbine axis and the generator axis from 3 to 6 meters, which allowed to increase the wrapping angle of the small pulley by $15 \%$.

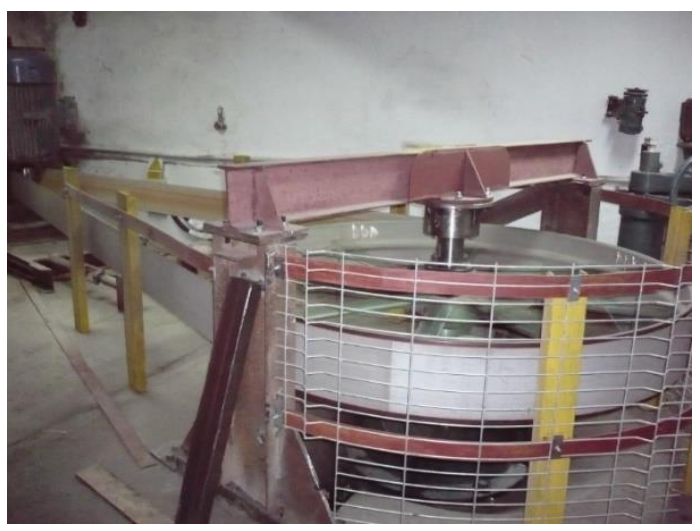

Fig. 7. Belt gear of a vertical axis.

The total scope of works allowed to eliminate lost motion and to reduce belt tension, as well as to increase the level of reliability of the plant. The power output increased by approximately $10 \%$ to 7.2 (fig. 8). 


\section{Comparison of energy production in 2008-2010.}

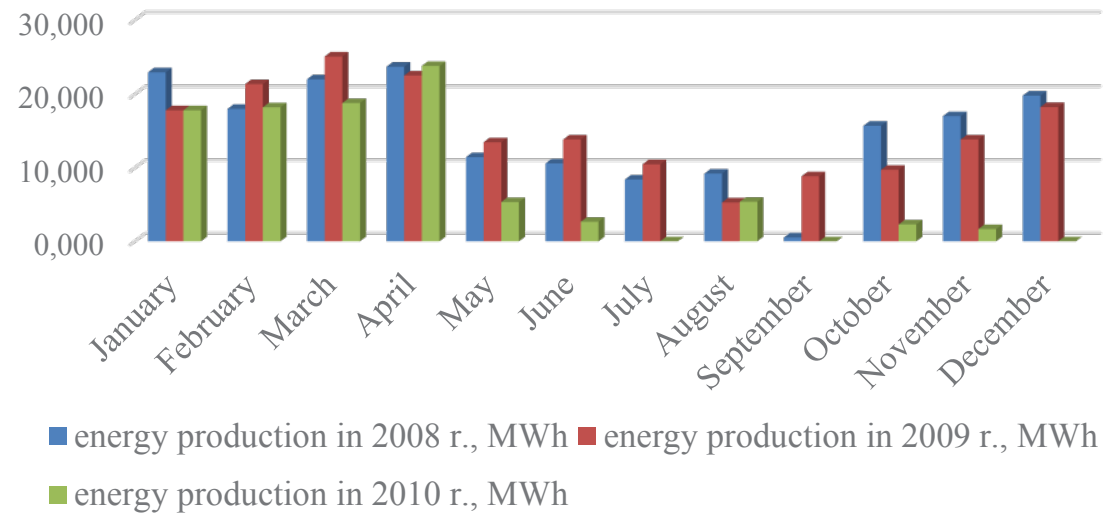

Fig. 8. Comparison of energy production in 2008-2010.

\section{Summary}

On the basis of the data presented, it was concluded that the efficiency of small hydroelectric plants can be increased by improving power transmission systems. The example described hereinabove clearly shows the increase of power production after the modernization of friction nodes and intermediate gears. The power output increased nearly five times (1.5 to 7.2).

\section{Acknowledgments}

This publication was made possible by the statutory activity of the Faculty of Environmental Engineering Wroclaw University of Science and Technology (W7/K2 0401/0069/16), financed by the Ministry of Science and Higher Education in 2017.

\section{References}

1. Ministerstwo Środowiska, Strategia Rozwoju Energetyki Odnawialnej (2000)

2. A. Hildebrandt, Pomeranian Economic Review (in polish), 10 (2014) (in Polish)

3. Statistical Pocketbook, EC, Renewable energy statistics (2016)

4. Eurostat, Energy from renewable sources (2016)

5. Z. Piec, A.Sambor, Energetics, 10 (2010) (in Polish)

6. Cieśla E., Paczkiewicz A., Inventory of a dam facility and a hydroelectric plant, "Promel" Water Projects and Land Reclamation Office in Opole (1983) (in Polish) 